\title{
Nanduty
}

\section{TERRITÓRIO, ETNICIDADE TERENA E A FESTA DE SÃO SEBASTIÃO - TERRA INDÍGENA BURITI, MATO GROSSO DO SUL.}

\author{
Rafael Allen (UFGD/ rafa_allen@hotmail.com)
}

\section{RESUMO:}

ESTE ARTIRGO ESTA RELACIONADO EM REGISTRAR A HISTÓRIA E A MEMÓRIA DOS TERENA DA TERRA INDÍGENA BURITI SOBRE SEU PRÓPRIO TERRITÓRIO. ATRAVÉS DOS DIÁLOGOS TRANSCRITOS NESTE TRABALHO, PERCEBE- SE QUE É INEVITÁVEL NÃO RECORRER ATÉ O RECORTE TEMPORAL DA GUERRA DO PARAGUAI (1864- 1870); TAMBÉM ABORDAREI O PROCESSO DE TERRITORIALIZAÇÃO VIVIDOS PELOS TERENA DE BURITI, A REELABORAÇÃO DA IDENTIDADE ÉTNICA PELO GRUPO E TAMBÉM A FESTA DE SÃO SEBASTIÃO COMO UM IMPORTANTE EVENTO SOCIAL QUE PROPORCIONA A ATUALIZAÇÃO DE ALIANÇAS ENTRE OS TERENA DE BURITI COM OUTROS GRUPOS ÉTNICOS. PARA OS TERENA DA ALDEIA BURITI, COMEMORAR E HOMENAGEAR SÃO SEBASTIÃO É PARTE DE SUA IDENTIDADE ÉTNICA, POSTO QUE SE CONSIDERAM CATÓLICOS; BEM COMO TAMBÉM CELEBRAM O OHEOKOTÍ, CERIMONIA TRADICIONAL TERENA. ATRAVÉS DA PERSPECTIVA DA FESTA DE SÃO SEBASTIÃO E SUAS IMPLICAÇÕES ESTE ARTIGO POSSUI FOCO CENTRAL NA ETNICIDADE TERENA E SEU TERRITÓRIO.

PALAVRA-CHAVES: TERENA DE BURITI, SÃO SEBASTIÃO, ETNICIDADE.

\begin{abstract}
:
THIS ARTICLE IS RELATED TO REGISTERING THE HISTORY AND MEMORY OF THE TERENA OF INDIGENOUS BURITI LAND ON ITS OWN TERRITORY. THROUGH THE TRANSCRIPT DIALOGS IN THIS WORK, IT IS INEVITABLE NOT TO GO THROUGH THE TEMPORARY CIRCLE OF THE WAR OF PARAGUAY (1864-1870); I ALSO WILL TREAT THE TERRITORIALIZATION PROCESS LIVE BY THE TERRITORIES OF BURITI, THE REELABORATION OF THE ETHNIC IDENTITY BY THE GROUP AND ALSO THE FESTA DE SÃO SEBASTIÃO AS AN IMPORTANT SOCIAL EVENT THAT PROVIDES THE UPDATING OF ALLIANCES BETWEEN THE TERENA OF BURITI AND OTHER ETHNIC GROUPS. FOR THE TERENA OF THE BURITI VILLAGE, TO COMMEMORATE AND HOMENAGEATE THE SEBASTIÃO IS PART OF ITS ETHNIC IDENTITY, WHEN THEY CONSIDER CATHOLICS; WELL AS ALSO CELEBRATE THE OHEOKOTÍ, TRADITIONAL TERENA CEREMONY. THROUGH THE PERSPECTIVE OF THE FESTA DE SÃO SEBASTIÃO AND ITS IMPLICATIONS THIS ARTICLE POSSES CENTRAL FOCUS THE TERNI ETHNICITY AND ITS TERRITORY
\end{abstract}

KEYWORDS: TERENA IN BURITI, SÃO SEBASTIÃO, ETHNICITY. 


\section{Nanduty}

\section{SÃO SEBASTIÃO E OS TERENA DE BURITI}

A Terra Indígena Buriti está localizada nos atuais municípios de Dois Irmãos do Buriti e Sidrolândia é organizada em oito aldeias: Córrego do Meio, Água Azul, Recanto, Oliveira, Lagoinha, Barreirinho, Olho D`Água e Buriti. Após a homologação da Terra indígena Buriti ela está contando em 2018 com 15 aldeias. Esta pesquisa etnográfica é realizada na aldeia Buriti, aldeia equivale a vila categoria nativa usada pelos mais jovens para identificar unidades sócio-espaciais menores, organizadas a partir de relações de parentesco, alianças política, regras sociais, práticas de sociabilidade e processos sócio-históricos em comum. Os mais velhos usam a categoria de troncos trabalhado por Pereira (2009), que possui o mesmo significado de vila: “...um grupo de parentes está articulado em torno da figura de um líder, geralmente um casal de velhos com vasta prole, sendo ancião identificado como tronco." (PEREIRA, 2009.p.49).

Geralmente, o casal que ocupa posição de tronco desempenha funções políticas e religiosas, são referências para o grupo de parentes, nas palavras de Pereira um propagador de um estilo de vida (PEREIRA, 2009.p.50). Independentes do tronco a que pertença, os Terena de Buriti se consideram participante de uma cultura Terena comum possuindo um reconhecimento essencial para se identificarem enquanto grupo étnico específico.

A aldeia Buriti é o lugar que ocorre a festa de São Sebastião e de importante impacto nas tomadas de decisões. Sendo privilegiada geograficamente por estar no centro da Terra Indígena Buriti e ser a primeira instaurada no processo de reserva congregando as outras sete aldeias ao seu redor.

Deste a década de 1920 os Terena da aldeia Buriti realizam a festa de São Sebastião, padroeiro da Terra Indígena Buriti. Essa festa começou a ser realizada através de uma promessa feita desde as primeiras décadas do século XX, quando os Terena da região foram acometidos por uma epidemia de febre amarela. Trata-se da maior e mais tradicional festa religiosa da aldeia, mantida até os dias atuais ultrapassando gerações. Possui grande importância na manutenção de redes de alianças, pois durante sua realização é possível 


\section{Nanduty}

ISSN:2317-8590

conhecer praticamente toda a comunidade e ter uma prévia visibilidade dos papéis sociais dos habitantes que ali residem.

Outro recorte temporal bastante frisado nas falas dos interlocutores recua nos registros até especificamente por volta das décadas de 1910, nesse período o Serviço de Proteção ao Índio (SPI) é criado e adota a politica de aldeamento. Acarretando várias violações dos Direitos Humanos em relação aos povos indígenas, como expurgação, genocídio e utilização de mão de obra na exploração e extração de riquezas na região em proveito do desenvolvimento. Perceberemos essas violações através dos relatos dos mais velhos da Terra Indígena Buriti.

É importante entender que o SPI foi criado em 1910, surgiu inicialmente como Serviço de Proteção aos Índios e Localização de Trabalhadores Nacionais, em um cenário que ocorria muitas mortes de índios por epidemias de doenças, ataques constantes de "bugreiros" (matadores de índios) além da intenção de "proteger" teve o objetivo de aproveitar os índios e integra-los à "civilização" essa integração seria a formação da mão-de-obra para o Brasil. O Marechal Cândido Mariano Rondon foi o primeiro diretor do órgão resultando na atuação de militares. A constituição de 1934 estabeleceu a politica indigenista como uma responsabilidade do governo federal.

Em 1937 a 1945 durante o Estado Novo, o governo Vargas promoveu a "Marcha para o Oeste", essa marcha visava à incorporação territorial e econômica de áreas do Brasil Central (os atuais estados: Mato Grosso, Mato Grosso do Sul, Goiás, Tocantins, além do sul do Pará). Esse momento foi acentuado por intensos conflitos de terra.

Esse contexto resultou em um processo de territorialização definido por Pacheco de Oliveira (1998), entendido como uma adaptação da organização social e da cultura Terena a uma nova situação histórica e política-administrativa, relacionada à vida em uma área bem menor se comparada com os 30.000 hectares que ocupavam até o primeiro quartel do século XX. Somam a isso as tentativas de dominação e subjugação que passaram a enfrentar por 


\section{Nanduty}

ISSN:2317-8590

parte de agentes dos órgãos indigenistas oficiais e de representantes das frentes expansionistas do Estado nacional.

$\mathrm{Na}$ atualidade os Terena sentem cada vez mais a importância em produzir e socializar novos conhecimentos sobre sua história, transmitido dos mais velhos para as gerações mais novas, como abordou Éder Alcântara Oliveira (2013), historiador terena da Terra Indígena de Buriti. Para ele são tentativas de revitalizar e ressignificar as histórias dos tempos dos avós e dos avós dos avós, às vezes chegando até cinco gerações; esse parece ser o caso dos festeiros de São Sebastião.

A Terra Indígena Buriti conta com 2.090 hectares devidamente regularizados, no entanto tramita na Justiça Federal um processo para a ampliação dessa área para 17.200 hectares, assunto este que tem sido estudado por diversos pesquisadores, como Eremites de Oliveira \& Pereira $(2007,2012)$, dentre outros autores.

Através desses encontros e da participação na festa pude interagir com a comunidade da Terra Indígena Buriti. Já na primeira visita, a festa de São Sebastião se mostrou como um importante aspecto de afirmação étnica dos Terenas da Terra Indígena de Buriti na atualidade.

Em seu livro "Cultura com aspas", Cunha (2009) nos remete a importância de diálogos da escuta e compreensão do que o outro está falando, que mais importante do que um pesquisador ir a campo e falar com os nativos é conseguir estabelecer um diálogo entre eles, conhecer sua história, trajetórias, lutas e interesses.

\footnotetext{
"Não se trata em Roma de falar como os romanos, trata-se, no entanto, de falar com os romanos. O que significa que a etnicidade é linguagem não simplesmente no sentido de remeter a algo fora dela, mas no de permitir a comunicação." (CUNHA. 2009, p.237)
}

Mesmo que a aldeia de Buriti festeje São Sebastião, um santo cristão/católico em sua origem, esses Terena tem consciência de que isso não faz com que eles sejam menos Terena. Ao contrário, o reconhecimento como terena de Buriti inclui em seu arcabouço cultural São Sebastião, como elemento terena. Este reconhecimento se dá mesmo frente a toda 


\section{Nanduty}

complexidade da sociedade nacional/ regional em que estão inseridos, e como sujeitos protagonizam sua história também a partir de apropriações do mundo do 'outro', englobados e englobando-os.

\section{A IMPORTÂNCIA DE SÃo SEBASTIÃo PARA A HISTÓRIA TERENA DA ALDEIA BURITI.}

Os dados presentes nesse artigo são frutos de pesquisas de campo iniciada no mês de agosto de 2012 até 2018 em paralelo ao levantamento e análise de bibliografia acerca do povo Terena, especialmente os Terena de Buriti; o caminho seguido foi do trabalho etnográfico. Segundo Geertz (2013) os dados de campo nos proporcionam realizar uma interpretação de segunda mão, pois quem faz a interpretação em primeira mão é o próprio 'nativo'. Cabe ao antropólogo fazer a interpretação das interpretações, por isso à importância em compreender o máximo possível às estruturas de significações, aproximando-se da visão de mundo do 'outro'.

$\mathrm{Na}$ Terra Indígena Buriti pude presenciar o fato de existir muitas igrejas evangélicas, uma delas, por exemplo, é a União das Igrejas Evangélicas da América do Sul (UNIEDAS). De fato, existe um fator relevante nessa informação, pois a maioria dos mais velhos geralmente são lideranças políticas e também religiosas, que divergem muitas vezes politicoreligiosamente dos católicos festeiros de São Sebastião. Frequentadores ou não, o fato é que os evangélicos jovens e mais velhos reconhecem a festa como um momento relevante na sociabilidade entre os Terena da Terra Indígena de Buriti.

Em seu livro Protestantismo à moda Terena, Acçolini (2015) com seu estudo sobre o protestantismo nas aldeias Terena especialmente na aldeia Bananal (localizada no município de Aquidauana- MS), expõe que:

"No caso dos Terena, a identidade surgida da conversão ao protestantismo é muito mais complexa, e por estar tão imbricada ali, sendo reconhecida também por quem não é crente, estamos vendo o protestantismo da Uniedas como um elemento integrante da cultura terena, no contexto histórico de interação entre essa sociedade e a nacional/regional”. (ACÇOLINI, 2015.p.27).

Comparando o Protestantismo da Uniedas do Bananal com a festa de São Sebastião, percebemos que São Sebastião da aldeia Buriti também possui suas complexidades e que a 


\section{Nanduty}

ISSN:2317-8590

ação, provocou mudanças nas relações simbólicas desse grupo. Uma nova identidade emergiu no reconhecimento de São Sebastião pelos Terena de Buriti. Este santo está tão pertencente por essa cultura, cuja estrutura pode ser "performática” (SAHLINS, 1990); tendo em vista que todo ano esse evento se concretiza através de gerações.

As estruturas performáticas valorizam a diferença que se apresenta nos acontecimentos circunstanciais e se colocam à frente sua própria ordem de significação. As estruturas prescritivas valorizam as semelhanças que se apresentam de acordo com seu arranjo social.

Se os Terena de Buriti reconhecem São Sebastião como padroeiro da Terra Indígena de Buriti, isso foi possível, pois a sociedade Terena parece se apresentar com uma estrutura performática. Em relação à apropriação de São Sebastião e sua simbologia entre esses Terena parece sintetizar sua visão de mundo, que valoriza e convertem o que se coloca como 'diferente' frente à sua estrutura social.

Claro que a inserção do cristianismo entre os Terena, ocorreu devido ao processo civilizador ocidental. Mas a São Sebastião foi atribuído o título de padroeiro, mas deixo claro que não foi "imposto" do externo para os Terena de Buriti, baseado na teoria de Sahlins podemos pensar que os Terena de Buriti são senhores de si mesmos. Os Terena de Buriti foram impactados pela: morte, causada pela febre amarela, a fome consequentemente proporcionada devido ao confinamento nas reservas e a limitação de seus territórios; o advento da exploração do capitalismo relacionando a localização de mão-de-obra com a pressão dos sistemas de produção sobre seu território.

Em particular foi pelo advento da febre amarela que os Terena tornaram este santo em padroeiro, converteram o seu significado à sua cosmologia e reelaboraram/ reelaboram a história Terena da Terra Indígena Buriti com legitimidade e o reconhecimento de todos em relação à São Sebastião. São Sebastião sendo do 'outro' foi reformulado, ressignificado segundo a cultura Terena. Mesmo que muitos Terena festejem São Sebastião, e frequentem igrejas evangélicas, muitos nunca deixaram de recorrer às práticas consideradas tradicionais, como nos exemplos de xamãs e purungueiras. 


\section{Nanduty}

Foi na festa de São Sebastião que conheci dona Isaura Alcântara (85 anos), conhecida como Cirica. Ela é xamã e também festeira de São Sebastião. Xamã é autoridade máxima da religião tradicional Terena. O Xamã também é chamado de purungueiro (a) devido a purunga que em outras etnias é designado como maracá, aquele chocalho que é usado em rituais. Ela me explicou que ela faz o Oheokoti que é um ritual que dura três dias, ele é muito poderoso, onde ela passa rezando. $\mathrm{O}$ auge do ritual é na madrugada da quinta- feira para sexta- feira santa. D. Isaura é conhecida como uma grande 'purungueira'.

Os xamãs Terena são designados em sua língua como Koixomuneti, chamados de purungueiros em português são sempre católicos. A sociedade Terena legitima homens e mulheres para tal função, são os purungueiros (as) que realizam o Oheokotí. Há estudos, como Acçolini (2015), que indicam que essa identidade que relaciona os Koixomuneti purungueiros ao catolicismo surgiu após a inserção do protestantismo entre esse povo.

Segundo o pesquisador Éder Alcantara. Conversando sobre a festa de São Sebastião ele disse que:

\footnotetext{
"nós aderimos São Sebastião na cultura Terena de Buriti como padroeiro da aldeia Buriti, há registros de freiras que moraram na aldeia Buriti e que aqui tem predominância católica. Também está sendo introduzida na aldeia Buriti influencias de religiões afro, além das varias igrejas evangélicas em toda T.I. Mas mesmo assim nós continuamos praticando a religião tradicional Terena" (caderno de campo, 2018.).
}

Durante os trabalhos de campo foi possível observar várias esferas que compõem a vida na vila Buriti, como as articulações políticas e as relações sociais que afirmam a identidade étnica, especialmente com a festa.

O evento não é apenas um acontecimento do fenômeno, ele se transformou devido à importância na interpretação do grupo, em relação à promessa do pai de seu Juscelino Bernardo Figueiredo nascido em 1941 e atual festeiro e um dos organizadores do evento. Podemos pensar que a festa de São Sebastião dos Terena de Buriti foi inserida pelo próprio grupo, de acordo com seu esquema cultural e é através da realização dessa festa que se adquiriu uma significância histórica que perpetua através de gerações. Essas modificações da 
estrutura e da história dos Terena de Buriti, transformou a festa de São Sebastião em um evento social e não em um acontecimento normal, proporcionou a reelaboração das identidades étnica pelo grupo.

\section{OS TERENA DE BURITI E A MEMÓRIA SOBRE O TERRITÓRIO}

Estudos realizados na década de 2000 atestam que a ocupação Terena no território que hoje é Terra Indígena Buriti se deu bem antes da titulação de terras a favor de particulares, o que se intensificou após a guerra entre o Paraguai e a Tríplice Aliança (OLIVEIRA e PEREIRA, 2007, 2012). Comumente nas narrativas registradas, os interlocutores destacaram atividades de caça, pesca, coleta e cultivo que desenvolviam antes da titulação das terras, ocupadas por fazendeiros. Também se lembraram de antigos 'trieiros' utilizados pelos Terena naquele tempo. Segundo Pereira (2009) os Terena em Buriti mantêm na memória, trieiros ou caminhos, considerados como:

"A malha de caminhos que funcionavam como suporte para uma rede de relações sociais: parentes e amigos se visitavam, circulavam presentes, estabeleciam acordos matrimoniais, alianças políticas, e combinavam a realização de festas de caráter lúdico ou religioso." (PEREIRA, 2009.p.51).

A quantidade e a conservação de trieiros ao redor de uma residência significam um status social elevado da família e uma ampla rede de relações. Até antes da década de 1930, os trieiros assumiam grande importância para os Terena. O reconhecimento desses trajetos por pessoas mais velhas acionam na memória recordações de antigos vizinhos, parentes, muitos deles já falecidos e da liberdade de viver na totalidade da extensão de seu território tradicional.

"A trajetória dos Terena quase sempre lembrada pela sua abertura para a exterioridade e também por sua 'índole pacífica'. Um fato histórico que contribui para esta afirmação foi a participação direta dos Terena na referida guerra, envolvendo soldados paraguaios e brasileiros na região. A participação Terena nesse conflito bélico se deu para garantir direitos sobre os territórios que ocupavam e também para defender o país. Assim o fizeram como soldados, mas também no fornecimento de alimentos, estadias, 'remédios', guias e informações ao Exército Imperial, haja vista o amplo conhecimento que possuem sobre a região.” (OLIVEIRA E PEREIRA, 2007, 2012). 


\section{Nanduty}

Mas a posse da terra que ocupavam foi interrompida quando o governo brasileiro, ainda na segunda metade do século XIX, passou titular grande parte do território Terena a fazendeiros e outros. Por este motivo, assim certa vez explicou uma importante liderança política de Buriti, falecida na década de 2000:

“...o ex-cacique Armando Gabriel, ao analisar a situação sócio-histórica vivida pelo grupo, argumentou que os Terena receberam do governo imperial apenas três botinas por lutarem ao lado do exército brasileiro na guerra contra o Paraguai: 'duas no pé e uma na bunda ( OLIVEIRA E PEREIRA, 2007).

Diante do esbulho sofrido em suas terras, muitos Terena enfrentaram grandes dificuldades na região, inclusive para sua reprodução física, pois foram expulsos das áreas onde praticavam atividades de caça, pesca, coleta e agricultura. Com isso muitos passaram a trabalhar nas fazendas, dentro do sistema de camaradagem, isto é, uma forma de exploração do trabalho indígena em fazendas de gado, relacionado a um sistema de dividas e dependência que lembra o trabalho escravo.

Os troncos antigos possuem lideranças idosas de famílias extensas e até mesmo de uma parentela, onde a principal atividade econômica tradicional é a agricultura. Esta situação foi presenciada quando fomos procurar o senhor Basílio Jorge para uma conversa. Ele estava com sua mulher trabalhando a terra para plantar feijão. Foi neste cenário que se iniciou a nossa conversa. Voltando da roça e chegando à sua casa, ele nos convidou para tomar um café, quando sentamos em bancos e redes que estavam no seu pomar iniciamos uma conversa informal, cujo conteúdo será descrito sucintamente na sequência.

Primeiramente, o senhor Basílio Jorge nos relatou que a Comissão Terena organizada em 1930 para ir à cidade do Rio de Janeiro tratar de assuntos relativos à terra da qual estavam sendo expulsos, explicou:

Na época, segundo o nosso conhecimento, que nós ficamos sabendo, foi o pai do Noel. Eles moravam na beira do Córrego do Meio, ali em cima né, onde hoje é conhecido como Engenho Velho. Até pouco tempo tinha uns palanques lá, que era dos engenhos, que eles utilizavam para fazer rapadura. Até hoje é conhecido como Engenho Velho. Então lá morava o pai do Noel. Noel justamente nasceu na beira do Córrego do Meio, lá em cima. Então na época foi o pai dele, que era o André Patrocínio, e o Sebastião. 
Não me lembro quem eram os outros dois... O André Patrocínio vendeu alguns bezerros para pagar a passagem e foram para o Rio de Janeiro, na época pedir a reivindicação, pra requerer o resto de nossas terras. E até hoje está nessa luta que está na justiça aí. Chegando lá era época de revolução [Revolução de 1930]. Mas não foram atendidos lá. Mas desde aquele tempo já vinha se arrastando, já tinha visão que aqui era pequeno demais. (Caderno de campo, Janeiro de 2013).

\section{Outra pessoa bastante lembrada por Basílio Jorge foi o cacique Joaquim Teófilo:}

O Joaquim Teófilo foi o primeiro cacique da região daqui né, lá do córrego pra cá. Mas só que ele morava não era aqui, era lá na zona do Paratudal, na outra comunidade de frente hoje da fazenda Água Clara, mas do outro lado de Buriti. Aonde hoje está no comando da fazenda Estrela, do finado Geraldo Corrêa. Então lá era a primeira comunidade indígena, onde o Joaquim Teófilo era o cacique. Mas aí a mando do proprietário na época, era o Agostino Rondon, ele era aliado com o primeiro chefe de posto aqui do SPI. Era Alexandre Honorato, segundo eles eram compadre, eram amigos e ele vinha muito aqui, e ele ia lá. Então eles tinham muito esse lado de comunicação. Ele convenceu o chefe de posto negociar para retirar os índios de lá. Hoje nós temos na história processual aí tudo o que aconteceu na época. Então o Alexandre Honorato, que era o primeiro chefe do SPI, consentiu que ele fosse buscar força policial em Aquidauana, não tinha Anastácio, era Aquidauana. Aí trouxe força policial de Aquidauana e expulsou os índios de lá. Aí que fundou a aldeia da Invernada. Eles vieram por aqui, a maioria atravessaram pela Invernada e fundaram a aldeia da Invernada. E nessa ocasião veio gente lá do Barreirinho também que era a primeira comunidade da região. Vieram para cá a família Reginaldo que estão hoje na Água Azul. Aí eles fundaram ali a aldeia Invernada. Aí mais tarde com essa ocupação indígena vieram permanecer na Água Azul. E aqui alguns vieram para cá, porque existia várias comunidades indígenas. Toda a região aqui tinha comunidade. Eu nasci no Córrego do Meio, o meu avô é um dos fundadores da comunidade aqui. Meu avô por parte de mãe se chamava João Batista Bueno. Eram em cinco irmãos: João Batista Bueno, Bonifácio Bueno, Agostino Bueno, Benedito Bueno e Gerônimo Bueno; eram cinco irmão por parte de mãe. Por parte de meu pai, meu pai, o pai do meu pai chamava João Jorge que era conhecido como João chalana, esses purungueiro feiticeiro. Eles eram Terena, mas por parte da minha mãe era Laiana. Daí cruzou Laiana com Terena, na qual hoje eu faço parte um pouquinho de cada. (Caderno de campo, Janeiro de 2013).

Essa fala remete ao descaso do governo brasileiro em relação à participação dos Terena na guerra contra o Paraguai, quando seu território foi transformado em fazendas de gado e sua expulsão da área foi feita com a participação de um funcionário do SPI.

O SPI foi criado pelos regimes militares com o objetivo de impedir que os índios atrapalhassem o 'desenvolvimento' do Brasil. No final dos anos sessenta, este órgão foi 
acusado de colaborar com roubo de terras indígenas e até praticar genocídios contra aldeias inteiras como nos explica Maybury- Lewis (1990):

"Surpreso por ter sido acusado internacionalmente de praticar genocídio contra seus índios, o Brasil acabou com o Serviço de Proteção ao Índio e o substituiu pela Funai Fundação Nacional do Índio - mas a Funai encontrou-se presa da mesma armadilha. Supunha-se que ela protegesse os direitos indígenas, mas o governo, esperava dela que encontrasse maneiras de impulsionar o 'desenvolvimento', comumente obtido às custas dos povos indígenas”. (Maybury- Lewis, 1990. p.12).

No caso do senhor Juscelino Bernardo Figueiredo, assim ele disse:

O meu pai veio para cá em 1902, porque meu pai foi da região de Miranda, de Agaxi. Me parece que ele chegou com dezessete anos aqui, quando eu estudei aqui era no posto para falar português. Quando eu me entendi por gente o chefe de posto que eu lembro era Angenor bem depois do tempo de Ubiratã e do tempo do coronel Nicolau Barbosa. Então já era bem pra cá, em 1955 por aí. Na época a lavoura aqui era feito no braço. Nós plantava arroz, feijão, mandioca, milho, banana... Não era mais do que isso. Mas só que aí a lavoura era cultivada no braço. Daí demorava muito, já tinha a época certa de plantar. Nós não fazia a roça hoje e amanhã plantava, vazia hoje e falava: "Vou esperar tal tempo". Tal dia em setembro, outubro principalmente, o arroz e o milho também. Se plantar o milho em novembro já não presta, tem que ser em setembro, mas era o tempo bom, o tempo de chuva, hoje está tudo misturado. Eu me lembro também da época da Captura(polícia estadual) no tempo do Getúlio Vargas. Bom isso daí quem falava para a gente era o meu avô, né. O que era a Captura? E o que a pessoa fazia? No passado não existia lei, a lei o que que era? Era quem tinha mais arma, aí formaram a Captura, a "Lei 44" eles falavam bem assim. E a captura fazia com as pessoas, mandado pelos comandantes deles e falou: "Se não trazer ele traz pelo menos a orelha dele". Meu avô contava assim. O meu avô sempre falava que ele morou em Campo Grande, no início de Campo Grande, né. O SPI teve um tempo que eu lembro comprava... Sei lá, gado, para a gente criar gado... Olha só que eu me lembro quem trabalhava em fazenda, trabalhava só em troco da comida pra tratar da família, a parte da educação não tinha, não se formava ninguém. Então nós perdemos muita terra, colocaram nós nesse pedacinho, a área era maior né e os fazendeiros invadiram que nem essa fazenda estrela era da aldeia, correntes era da aldeia, o Canastrão, aqui era da aldeia, então os fazendeiros foram... É terra devoluta e até hoje. Muitas vezes o patrício... Está nesse pensamento até hoje, tem o direito. Ter tem né? Mas os fazendeiros querem o dinheiro, até hoje eles matam e a justiça não faz nada. É o que a gente lembra dessa Invernadinha que a aldeia era lá. Então o meu avô chegou aqui foi nessa época da guerra né? $\mathrm{Na}$ verdade aqui era o Paraguai, não tinha nada certo ainda. No passado em 1968 só aqui, Córrego do Meio, não tinha a Lagoinha, Água Azul. Só tinha Água Azul, não tinha outro lugar. Buriti era só Buriti. Eram três aldeias e hoje são nove. Então na época do meu avô, ele foi cacique que... primeiro o cacique Teófilo ele não tinha escolaridade. O Farias também não. Aí meu avô morava em Patrimônio Aroeira. Souberam que ele estava trabalhando em fazenda, foram lá 


\section{Nanduty}

ISSN:2317-8590

buscar ele, por sinal ele tinha uma caligrafia muito boa. (Caderno de campo, Janeiro de 2013).

Considerando que o discurso indígena muitas vezes esta pautados em categorias ocidentais, nesses relatos podemos observar este movimento de etnificação e a ressignificação da cosmologia após contatos, apropriando categorias ocidentais e convertendo á sua estrutura social. Segundo Bruce Albert (2002):

“...é a capacidade de executar tal articulação que faz os grandes líderes interétnicos. São esses efeitos de interação e retroação que dão ao discurso político indígena contemporâneo um interesse etnográfico especial." (ALBERT, 2002. p.242).

A festa de São Sebastião na aldeia Buriti é importante por muitos motivos, dentro os quais é um dia, para se lembrar da epidemia da febre amarela, do inicio de um processo de territorialização de acordo com Pacheco de Oliveira (1998), uma mudança na organização social e cultural Terena à uma nova situação histórica, relacionada diretamente com a fome devido a diminuição abrupta de seu território tradicional. É um momento de recordar dos entes queridos que deixaram saudades, ou dos que estão doentes. Essa festa também reequilibra as alianças internas e externas e aciona a solidariedade entre os indígenas principalmente do estado de Mato Grosso do Sul.

\section{AS TROCAS INTERÉTNICAS E SUAS ALIANÇAS}

Ainda no Chaco os Terena mantiveram profundas relações com Mbaya Guaykuru a ponto dos Terena secularmente terem incorporado à sua estrutura social de metades, as camadas hierárquicas deste outro povo.

A relação mantida entre os Guaná/ Terena e os Mbayá-Guycurú caracterizava-se mais pela troca que pela sujeição violenta. Ao contrário de outros povos, como os Chamacoco, que eram escravos dos Mbayá-Guaycurú e os Chané, escravizados pelos Guarani-Chiriguano, os Guaná mantinham suas unidades político- econômicas e articulavam-se com os Mbayá por meio de visitas periódicas. Durante estas visitas os "senhores cavaleiros" tinham a obrigação moral de presentear seus anfitriões com o que estes exigissem (Carvalho.1992,p.467). Em contrapartida, os Guaná/ Terena os abasteciam com alimentos provenientes de suas roças. 


\section{Nanduty}

ISSN:2317-8590

Podemos imaginar o alcance da aliança entre estes dois povos através de um mito dos Mbayá-Guaycurú, onde os Guaná aparecem como os primeiros homens que foram retirados da terra pelo ser criador supremo deste povo, Gonoenhodi. Nesse mito, que conhecemos fragmentariamente, os Guaná são tirados da terra e recebem desse ser supremo a agricultura.

“...O Enganador, que é a outra divindade do panteão indígena, percebeu então que os Mbaiá haviam sido esquecidos no fundo do buraco e os fez sair dali; mas como não sobrava nada para eles, tiveram direito à única função, ainda disponível, a de oprimir e explorar os outros. Já houve contrato social mais profundo do que este?" (LeviStrauss, 1998,p.170).

Cardoso de Oliveira (1965/1966) e Altenfelder Silva (1949), pautados em outros autores, afirmam que a sociedade Terena possuía uma estrutura social tríplice, marcada por relações assimétricas: os próprios Terena, que estavam divididos entre Naati, a nobreza e os Waherê-txané, as pessoas comuns, e os Kauti, ou cativos, que pertenciam a outros grupos étnicos. Tanto Altenfelder Silva (1949) como Levi-Strauss (1998) colocam que esta estratificação social de fato não pertencia aos grupos Guaná, mas foi incorporado à organização social Terena/Guaná dos Mbayá-Guaycurú pela proximidade com que viviam e reconhecimento da estrutura social destes, também por conta das necessidades dos Guaná frente aos Mbayá, como por exemplo, por proteção. Por seu lado, os Mbayá também se beneficiavam dessa aliança especialmente pelos bens agrícolas cultivados e fornecidos pelos Guaná.

Na análise de Barth (1969) um grupo étnico é um tipo organizacional, cuja sociedade utiliza de diferenças culturais para fabricar e refabricar individualidades diante de outros grupos, com quem estava ou esta em um contexto de interação social. Sempre houve interação dos Terena com outros povos entre esses estão a aliança com Mbayá-Guaykurú.

Com a Guerra da Tríplice Aliança a interação com o "branco" se intensificou, e mais ainda no processo de territorialização com a intensa integração da agropecuária na região.

Segundo Barth (1969) é um equivoco pensar que uma condição de isolamento pode explicar os elementos constituidores de um grupo étnico e assim propõem desfocar a atenção 
das culturas enquanto unidades isoladas para os processos identitários, que devem considerar contextos precisos e percebidos também como atos políticos, proporcionando a circulação das tradições culturais de diferentes unidades sociais.

Filho de Mbyá- Guaykurú e Terena, Noé Patrocínio assim disse:

Meu pai era o André Patrocínio, ele era descendente de Guaicuru, falante. E minha mãe era a dona Joaninha Jorge. Ela era irmã do pai do Basílio Jorge. Ele é meu primoirmão. Eu nasci em 1932. O que lembro do meu pai que eu escutava histórias, foi que ele vendeu uns bezerros que ele tinha para ajudar na viajem na época do cacique Ernesto Filho. Eles organizaram uma comitiva entre quatro pessoas e o cacique achou melhor meu pai fazer parte dessa comitiva. Bom a comissão foi para o Rio de janeiro, mas lá enrolaram muito eles. Como ele chegou lá na época da revolução, ele não conseguiu falar com ninguém. A viagem era muito demorada. Naquele tempo não tinha estrada para sair daqui e ir para Campo Grande para pegar o trem, eles foram de cavalo. Depois lá pegou o trem e lá tinha os dias certos que o trem passava. Só que eles foram. Porque nesse tempo já sabia que a aldeia aqui seria muito pequena e aí assim foi isso que ele me contou. Eu nasci no Córrego do Meio e quando eu era pequeno meus pais se mudaram daqui para eu estudar, mas depois voltei. Sinto que aqui é o meu lugar. Eu tive tantas coisas boas fora da aldeia e por que eu não fiquei por lá? Não criei raízes em lugar nenhum, aqui, aqui eu criei raízes profundas, mas por quê? No processo de reaver as terras daqui, a pessoa principal depois do cacique era o meu pai né? $O$ personagem no relatório do reconhecimento da terra aqui, $O$ personagem central ali depois do cacique que organizou, que viu que a terra era pequena, aí o próprio personagem foi o meu pai. E eu tenho sorte porque está escrito no relatório, têm documentos. Ele sempre foi lembrado e todos fazem referencia ao André Patrocínio, ele era Guaicuru, em certo momento teimoso e durão, mas de coração mole. Meu pai não gostava de evangélico, tanto que uma certa vez ele aprontou. Ele sempre teve cavalo Guaicuru né, cavaleiro, subiu no cavalo e foi para igreja, foi de plano feito. Jogou o reio no lombo, o plano dele era surrar o pastor né? Foi lá para isso, estava decidido, entrou na igreja e esperou o momento da pregação e tal. E ele não teve coragem, ele amoleceu, não teve coragem de surrar o pastor não. E a partir daquele dia passou a modificar a vida dele, e ele festava São Sebastião, antigamente lá no Assoalho com os pé de bode. Ele era festeiro, ele participava de todo o pisero. Mas aí modificou a vida dele, ele se converteu para um evangélico muito fervoroso. E aqui em Buriti, o Buriti até hoje são rebelde para com os evangélicos. Então se ele era festeiro, festejava junto. Quando ele se converteu, se afastou dos amigos e companheiros dele. Aí eles ficaram com raiva. O meu pai não tinha tristeza e aí os companheiros dele sentiram falta da companhia. A minha mãe era muito simples, como toda mãe, ela era muito amorosa com os filhos. (Caderno de campo, Janeiro de 2013). 


\section{Nanduty}

É importante ressaltar que sempre houve interação entre os diversos povos pertencentes ao Chaco Paraguaio alguns com relações harmoniosas e outros com relações conflituosas.

A situação de vulnerabilidade, insegurança e violência a que os Terena de Buriti passaram a sofrer, se iniciou pós-guerra do Paraguaio, agravando no período militar com o cruel projeto nação brasileira, legitimado pela ditadura. Foi este o contexto do processo de esbulho que sofreram em suas terras e também do processo de territorialização a que foram submetidos na configuração de reserva indígena.

\section{PORQUE REALIZAMOS A FESTA DE SÃO SEBASTIÃo?}

A festa de São Sebastião é composta por várias etapas, marcadas por rituais de devoção em busca de uma graça ou pagamentos de promessas. No dia dos finados dois de novembro, é a data que se inicia a peregrinação, marcada por uma missa. A missa tem a intenção de relembrar dos mortos, afastarem os maus espíritos e abençoar os folieiros em seus sacrifícios, com a intenção de que a arrecadação de presentes para a realização da festa do Santo seja generosa. Nessa missa tem a presença dos folieiros e consequentemente se lembra da epidemia de febre amarela que morreram muitos Terenas. $\mathrm{O}$ atual festeiro Juscelino Figueiredo me explicou que a festa de São Sebastião deu inicio devido a muitas mortes causada pela epidemia:

A festa de São Sebastião, foi meu pai quem fez a promessa de todo ano fazer a festa. Naquele tempo não tinha médico, não tinha remédio, só raiz e benzeção, oração né? Até meu pai não ocupava muito da raiz, mas tinha a capela dele e o poder com Deus. Houve essa epidemia de febre amarela e quando teve essa epidemia tava matando quatro, cinco por dia e o povo não tava vencendo de fazer o enterro das pessoas, né? Chegaram enterrar as pessoas até sem caixão, né? Fizeram caixão até de ripa de taguarusu. Aí meu pai falou: "Vou fala com Deus!" Fez o pedido, né? De comemorar o dia de São Sebastião durante a vida dele, dê pai pra filho. (Entrevista feita com Juscelino Figueiredo, por Rafael Allen e Roselaine Miguel no dia 22 de Janeiro de 2013).

Os "folieiros", geralmente são pessoas que fizeram alguma promessa, o papel deles é percorrer um caminho especifico fora da aldeia, passando pelas fazendas da região, com a 
bandeira de São Sebastião, cantando, tocando e rezando em cada casa, chamada por estes de pouso com a finalidade de arrecadar doações para a festa do santo. Os festeiros são pessoas que não percorrem essa peregrinação, a participação deles é no dia da festa celebrando São Sebastião.

As doações recebidas pelos "folieiros" são diversas como: macarrão, arroz, mandioca, legumes, vacas inteiras, dinheiro, cada doador doa o que pode. A mobilização nessa etapa inicial vai além da Terra Indígena Buriti; nota-se do grande número de pessoas envolvidas que contribuem para a realização dessa festa. Esse evento pode ser caracterizado como um fenômeno social 'total', pois em primeiro lugar não é uma simples troca de bens entre indivíduos e sim coletividades apesar de ter no primeiro momento uma característica voluntaria, no fundo é rigorosamente obrigatórias, mutuamente sendo feito por pessoas morais: clãs, tribos, famílias (MAUSS, 2013).

“Ademais, o que eles trocam não são exclusivamente bens e riquezas, bens móveis e imóveis, coisas úteis economicamente. São antes de tudo, amabilidades, banquetes, ritos, serviços militares, mulheres, crianças, danças, festas, feiras... Enfim essas prestações e contraprestações se estabelecem de uma forma, sobretudo voluntária, por meio de regalos, presentes, embora elas sejam no fundo, rigorosamente obrigatórias, sob pena de guerra privada ou pública.” (MAUSS, 2013, p.191.)

Vale ressaltar que em uma das minhas visitas ao senhor Noé Patrocínio, me contou que este caminho específico é a antiga configuração da aldeia Buriti, a Invernada. Locais de antigas habitações, roças, áreas de pesca, caça e coleta e pelo caminho, locais de antigos cemitérios e outras referências simbólicas.

A ocupação da área objeto da perícia por proprietários particulares já duram várias décadas. Nesse período, muitos Terena de Buriti trabalharam para os fazendeiros ou realizavam expedições clandestinas de caça, pesca e coleta. Isso permitiu que muitos índios mantivessem até poucos anos trânsito relativamente frequente por algumas áreas. O trânsito pela área objeto da perícia e os relatos dos eventos passados transmitidos através de gerações mantiveram com toda certeza, "vivos os laços que unem os índios da etnia Terena às terras em questão". O conflito gerado pelas tentativas de reocupação e os estudos e levantamentos realizados entre população ativou a memória sobre a antiga ocupação, cujo conhecimento vem sendo sistematicamente repassado para as novas gerações que não nasceram nem viveram nessas áreas. (EREMITES DE OLIVEIRA e PEREIRA. UFGD, 2012.p.205) 


\section{Nanduty}

ISSN:2317-8590

Nota- se assim o importante papel que desenvolvem os folieiros, eles além de devotos assumem o importante papel de agentes históricos, a peregrinação possibilita para que a categoria jovem possa conhecer o passado do seu território e de seus antepassados, além da flora e fauna da região sendo um complemento no ensino e aprendizagem Terena. Nem todo ano a quantidade de folieiros é a mesma, ela varia.

Eles passam em cada casa com a bandeira e realizam três cantos. O primeiro canto anuncia a chegada, quando é feito o pedido de recebimento da bandeira pelo morador da casa. O morador recebe a bandeira com a imagem de São Sebastião e em curto período de tempo ele leva a bandeira em todos os cômodos da casa. Junto á essa ação este morador faz orações pedindo a São Sebastião proteção, felicidade e saúde.

Quando o segundo cântico se inicia, ele anuncia a hora da despedida. O morador retorna neste momento com a bandeira no cômodo em que estão os folieiros, geralmente na sala quando não se tem varanda. Esse também é o momento em que o morador formaliza a doação para a realização da festa.

Logo após do segundo cântico se inicia o terceiro que especificamente é direcionado á família da residência que esta sendo visitada e quem recebeu a bandeira, se ajoelha e faz as últimas orações. Após esse ritual os folieiros seguem para as próximas residências que continuam com o mesmo ritual. Eles fazem essa peregrinação até o dia dezenove de Janeiro, quando a bandeira retorna para Buriti e anuncia o inicio da festa e o dia de São Sebastião.

Observo que não é só o momento da festa que acontece a manutenção das alianças, a peregrinação é um momento complexo que revitaliza as relações preexistentes. É uma dádiva receber a bandeira de São Sebastião em sua casa e a graça do santo. Um momento de puro prestígio entre os devotos e como retribuição uma doação para a festa do Santo. Podemos pensar na reciprocidade no ato de dar, receber e retribuir de Mauss (2013).

(...) dois elementos essenciais do potlatch propriamente dito são nitidamente atestados: o da honra, do prestígio, do mana que a riqueza confere, e o da obrigação absoluta de retribuir as dádivas sob pena de perder esse mana, essa autoridade, esse talismã e essa fonte de riqueza que é a própria autoridade. (MAUSS, 2013.p.195) 


\section{Nanduty}

ISSN:2317-8590

No primeiro momento as doações do ano anterior, são retribuídas com a graça do santo e a visita dos folieiros no ano atual, as doações do ano atual serão retribuídas no próximo ano, assim mantem a aliança que se renova a cada ano sendo necessário um período de tempo para retribuir, o santo não recebe á débito, mas á crédito.

A comparação feita por Mauss (2013) é relacionada ás dádivas feitas e retribuída com o sistema de compra e venda. Para ele o sistema da dádiva apesar de levar em consideração o religioso ele é complexo, de uma economia extra doméstica e muito desenvolvida. A dádiva implica a noção de crédito e juros. O "tempo" é necessário para executar qualquer contraprestação. É um sistema de direito e de economia no qual se consomem e se transferem constantemente riquezas consideráveis.

Existe a promessa de no ano seguinte fazer doações maiores ao santo se alcançarem tais graças e essa nova dádiva é paga no ano seguinte que já será o retribuir da antiga dádiva do santo e conseguir novas. "O mais importante, entre esses mecanismos espirituais, é evidentemente o que obriga a retribuir o presente recebido" (MAUSS, 2013.p 193).

No dia de 19 de janeiro de 2013, com o retorno dos folieiros com a bandeira na vila Buriti, formou-se uma multidão de devotos e moradores da região e de outras regiões. Este é o momento da prática, a ação de intensa devoção ao santo, muitos beijam, se benzem e fazem saudações à bandeira de São Sebastião. Os folieiros passam por todas as casas que estão no caminho para a capela.

No centro da vila de Buriti, a família Isabel também está construindo uma capela, essa família é responsável por um dia da festa (o dia 18). Essa festa não é a oficial da promessa feita pelo pai do seu Juscelino, mas é uma festa também para o santo. A família Isabel é vizinha da família Figueiredo, sendo a última casa a receber a bandeira antes do retorno da bandeira para seu Juscelino.

Alguns amigos de Buriti me explicaram que o momento do retorno da bandeira na capela e o recebimento pela família Figueiredo é denomina de recolhida. Um momento muito 


\section{Nanduty}

ISSN:2317-8590

emotivo para os devotos de São Sebastião. Após 79 dias levando a bandeira em várias casas da região, os folieiros encerram a sua missão. Neste momento a capela se torna pequena para tantos fiéis, os folieiros carregaram a imagem de São Sebastião e a bandeira fora da capela, dão três voltas em torno desta e um dos folieiros entregam a bandeira à família Figueiredo. A esposa de seu Juscelino recebe a bandeira muito emocionada e seu marido agradece aos folieiros e festeiros presentes na festa. Seu Juscelino me explicou que:

(...) a recolhida do santo é o momento mais esperado. A gente fica esperando lá na frente aquele povão acompanhando. A minha mulher recebe a bandeira e leva pra frente e minha parte é agradecer os folieiros e todos que participaram. (Caderno de campo, Janeiro de 2013).

Logo após a recolhida inicia-se o jantar, por volta das 17 horas. A comida da festa de São Sebastião é abençoada pelo padre de Sidrolândia. Esse ritual com a comida é para que a comida de todo dia seja em abundância.

Há toda uma organização na elaboração do jantar, muitas vezes o preparativo da comida se inicia no dia anterior. Existe uma divisão de tarefas relacionada ás atividades consideradas masculinas ou femininas. O preparo do churrasco, deste o carnear a vaca, os carneiros, preparar esta carne, fazer uma grande valeta, confeccionar os espetos de bambu, fazer o fogo, assar e servir o churrasco é de responsabilidade predominantemente masculina.

$\mathrm{Na}$ festa de 2013 foram doadas onze vacas e cinco carneiros para serem carneados e mais cinco vacas para serem leiloadas. As designações das doações acontecem durante o pouso da bandeira na casa do doador. Ele define se a doação vai para o churrasco do dia da festa ou para o leilão. Nessas doações misturam-se os sentimentos e as pessoas.

Devido ás emoções, comoções não só na Terra Indígena Buriti, mas em toda a região, acredito que a festa de São Sebastião é um momento de misturas. O grande número de pessoas envolvidas que contribuem através de doações (principalmente de alimentos) e serviços para a realização desta festa não é um acontecimento diário e pode ser caracterizado como o evento que proporciona um fenômeno social 'total', pois em primeiro lugar não é uma 


\section{Nanduty}

ISSN:2317-8590

simples troca de bens entre indivíduos e sim entre famílias, possibilitando o jantar a São Sebastião onde todos são convidados.

"Trata-se, no fundo, de misturas. Misturam-se as almas nas coisas, misturam-se as coisas nas almas. Misturam-se as vidas, e assim as pessoas e as coisas misturadas saem cada qual de sua esfera e se misturam: o que é precisamente o contrato e a troca." (MAUSS, 2013.p.212).

Pude perceber que o churrasco é o complemento do jantar, sendo o masculino o provedor da proteína. As designações ao sexo feminino na preparação do jantar é o cozimento dos carboidratos como: mandioca (xúpu), arroz (nakaku), macarrão (mangarão) e feijão (peixau), além de prepararem a farofa e a salada.

No dia anterior a festa o espaço cozinha se tornou um lugar de encontros entre parentes e amigos da vila e de outras regiões, neste momento de descascar mandioca, lavar e cortar alimentos, manusear o fogo assume uma atmosfera política. As conversas na cozinha falam de misturas de comidas, misturas de pessoas e misturas de sangue (surgimento de novos casais), não só da vila de Buriti, mas também de outras aldeias próximas e distantes devido às visitas de parentes e amigos. A preocupação está em torno do corpo, deste do nascimento até a vida adulta, com todos os seus rituais de passagens e claro sobre o território fundamental para que esse corpo se desenvolva sob a lógica Terena.

Lévi Strauss (1969) articula a circulação de mulheres, palavras e comidas formadoras de toda estrutura social. Na preparação do jantar da festa de São Sebastião, o espaço prescritivo ás mulheres são as cozinhas. Elas circulam entre as cozinhas próximas, e com elas as informações e as comidas.

Carneiro (2015) aborda que a comida e a cozinha foram em muitas etnografias pensadas apenas como "produção de sociabilidade" e deixou de lado o seu importante papel de construção de corpos. Ela recorre a Lévi-Satrauss (1964; 1965) que argumenta: a cozinha como lugar de encontro entre natureza e cultura. 


\section{Nanduty}

O alimento pode ser pensado como natureza em si e o modo de preparo desse alimento emerge a cultura. As técnicas culinárias, o conhecimento dos alimentos, os temperos e a preferencia de paladar é passada através de gerações. Para Lévy-Strauss (1991) é através da culinária e sua complexidade, que torna um dos meios que a natureza se transforme em cultura.

Percebi que neste contexto predominantemente feminino, exerce um grande poder de influência nas tomadas de decisões e articulação do movimento político. A cozinha é o principal espaço para o desenvolvimento de corpos, pois é na cozinha que se prepara o alimento que vai alimentar as necessidades do corpo e proporcionar um entendimento das relações sociais. Nela tornam visíveis práticas que intervém no corpo, práticas que possuem conhecimento sofisticado das relações humanas, do próprio corpo e dos alheios, da natureza e do território.

Há muitos voluntários ajudando no servir a comida, geralmente são mulheres que servem as comidas feitas por elas. Forma-se uma fila em que cada participante da festa vai servindo o que lhe agrada.

O comer junto (fazer as refeições) com os parentes independentes de serem por consanguinidade ou por afinidades é uma das características dos Terena de Buriti, sinônimo de companheirismo e união, independente de fartura ou da falta de alimentos, todos estão juntos diariamente. É importante ressaltar que o tipo ideal dos Terena é viver entre parentes e o comer junto concretiza esse ideal todos os dias.

O jantar é um momento de distração e confraternização, este momento é próprio para a interação e conhecer as pessoas vindas de fora. Conversei com algumas pessoas vindas de outras cidades para o evento, como um grupo de amigos vindo de São Paulo, outras famílias vindo de Corumbá, além de pessoas de Campo Grande, e muitos indígenas de Dourados, Nioaque e Aquidauana. 


\section{Nanduty}

ISSN:2317-8590

Nesse momento uma criança de aproximadamente uns sete anos Terena me trouxe um prato de comida com muita carne, arroz, macarrão, mandioca e salada. Agradeci a ela. Procurei um lugar para sentar e avistei a dona Isaura a xamã da vila Buriti, conhecida como Cirica de 85 anos, pedi permissão para sentar ao lado dela. Sempre quando vou para a Terra Indígena Buriti depois desse encontro, visito a dona Isaura. Ela me convidou para uma benzeção e me contou que vem muitos índios e brancos solicitar os trabalhos dela. Vem gente de outros estados e que os principais trabalhos que ela faz são relacionados à doença que muitas vezes a medicina ocidental não consegue achar a causa ou diagnosticar a doença e também sobre inveja, "quebranto" que deixa a pessoa doente e nada dá certo:

Esses dias veio um rapaz com a mãe dele do estado de São Paulo, levou ele num monte de doutor lá e não conseguiu descobriu o que ele tinha. Falei para ela voltar na sexta feira santa com ele, porque é o dia mais forte para cura. Ele voltou, comecei meu trabalho de manhã com ele e a noite começou a sair dele vários sapinhos. Depois desse dia ele curo. (Caderno de campo, Janeiro de 2013).

Acabei sendo motivado a perguntar a ela quando ela começou atender como xamã.

Sempre fui de ver as coisas, e também sei os remédio bom... minha prima era a xamã mais poderosa da aldeia conhecida como Senhorinha...antes dela morre ela pegou minha mão e olho no meu olho e falou: "todo o poder que tenho dentro de mim passo pra você e todo poder dentro de você passa para mim." Assim comecei, quando ela se foi, ficou eu, e um dia vou passar esse meu poder para outra xamã, ele não pode morrer comigo." (Caderno de campo, janeiro de 2013).

Fui pesquisar sobre a Senhorinha, o nome dela era Laurelina Alcântara Batista, nascida entre 1928 a 1929 no córrego do meio, ela foi uma xamã muito respeitada, prima da dona Isaura. Segundo Eremites e Pereira (2012):

Laurelina Alcântara Batista, senhorinha, 83, é hoje uma das xamãs ou porungueiras mais respeitadas e procuradas em Buriti. Também atende muitos brancos da região, alguns inclusive de outros Estados como São Paulo. Segundo disse, "ela segue o oficio de xamã porque este é patrimônio de seu tronco." ( EREMITES e PEREIRA, 2012. P.184).

Mesmo em uma festa de um santo católico, encontrei uma xamã Terena, que me possibilitou conhecer sua história e me falou que o oficio tradicional religioso Terena é 


\section{Nanduty}

transmitido de geração á geração dentro da mesma família. Mesmo com São Sebastião ela atende muitos índios e não índios.

Após o jantar, os moradores presentes de todas as vilas (exceto os evangélicos) e os visitantes de fora, formaram uma multidão e percorreram as principais ruas da vila de Buriti, rezando e cantando um momento de muita emoção. Muitas pessoas se vestem com roupas da cor da bandeira, outras fazem promessas ou pagam a promessa da graça recebida.

Neste momento os fiéis seguiram para o galpão da festa do lado da capela, nesse local o padre vindo de Sidrolândia aguardou a multidão para iniciar a grande missa. Com a chegada dos fiéis o padre celebrou a missa. Todos os presentes participaram intensamente com cantos e rezas a maioria dessas são pedidos de saúde e contra a inveja.

Após o término da grande missa, a comissão organizadora do baile e do leilão assumem o evento. O baile é um momento de diversão e celebração, vários grupos musicais animaram a festa, geralmente estilos musicais como o sertanejo, polca paraguaia, chamané e vanerão. Entre as apresentações dos cantores o leilão ocorre, as vacas que foram doadas especificamente para o leilão, foram todas leiloadas.

Um dos festeiros me contou que esse dinheiro arrecadado com o leilão se transforma em benfeitoria para a vila Buriti como reformas no galpão e na capela. Mas principalmente são destinados aos gastos com o evento, como atrações musicais, seguranças, equipamentos de luz e som, gasolina para translado de pessoas e de doações. Esse dinheiro primeiramente é destinado à logística da realização da festa, o excedente é destinado para benfeitorias dos espaços acima citados. Nesse ano o baile durou até o amanhecer, por volta das cinco horas da manhã os músicos começaram a desmontar os equipamentos de som e muitos festeiros começaram ir embora.

Após as festas de São Sebastião da aldeia Buriti, foi possível averiguar a importância desse santo que, apesar de santo católico, foi ressignificadoe é parte dos elementos culturais que formam e transformam a identidade Terena. 


\section{Nanduty}

ISSN:2317-8590

\section{CONSIDERAÇÕES FINAIS}

Este artigo teve como objetivo, registrar a memória de pessoas idosas da etnia Terena que vivem na região. A busca pelo conhecimento e o registro da própria história, faz o principal uso da memória. O foco central é o processo de ressignificação de São Sebastião e a afirmação da etnicidade Terena, essa proposta teve como objetivo de observar a reelaboração do xamanismo e as tentativas de revitalizar e ressignificar as histórias sobre o próprio território, a partir do contexto dos Terenas de Buriti que travam uma longa luta política por seu território tradicional.

Mesmo que a aldeia de Buriti festeje São Sebastião, esse grupo tem consciência de que isso não faz com que eles sejam menos Terena. A etnicidade sugere uma trajetória histórica e uma origem. Através do processo de territorialização formulou-se uma identidade étnica própria, nelas as atualizações não anulam o sentimento de referência à origem, mas as reforçam. São Sebastião pode ser pensado em uma dessas atualizações, a devoção desse santo proporcionou a reelaboração das identidades étnica pelo grupo.

Os Terena de Buriti são senhores de suas vidas e guerreiros de sua história. Esse evento social tornou uma significância histórica para esse grupo, relembrando de um difícil período que configurou o sistema da vida em reserva. Mesmo com São Sebastião muitos índios e brancos recorrem ao xamanismo, buscando nas práticas tradicionais religiosas Terena, conforto, saúde, paz e proteção

As divisões de tarefas para o preparo da festa e especificamente do jantar, me forneceram a perspectiva de gênero. Esse momento possibilitou perceber o quanto o papel das mulheres é importante para a educação das crianças, manutenção de práticas de sociabilidade e a realização da festa de São Sebastião. A cozinha um espaço feminino, que aparentemente se dá apenas para o preparo dos alimentos, tem um poder de influência muito grande nas construções de corpos. Além disso, também é um espaço onde se discute todo universo da aldeia, tanto feminino quanto masculino e possibilita a manutenção de alianças. 


\section{Nanduty}

\section{REFERÊNCIAS BIBLIOGRÁFICAS}

ACÇOLINI, G. 2015. Protestantismo à moda Terena. Dourados, MS:Ed. UFGD.

ALBERT, B. 2002. O ouro e a queda do céu. Uma critica xamanica da economia politica da natureza (Yanomami). In: Pacificando o Branco, A. Rita. São Paulo: Editora UNESP: Imprensa Oficial do Estado.

ALCANTARA OLIVEIRA, E. 2013. História dos Terena da Aldeia Buriti: memória, rituais, educação e luta pela terra. Dissertação de Mestrado em História - UFGD, Dourados.

ALMEIDA, C.P. Dinâmicas familiares, fluxos de pessoas e história em aldeias Terena. Dissertação de mestrado - UNB, 2013.

ALTENFELDER SILVA,F. "Mudança Cultural dos Terêna”. Revista do Museu Paulista,n.s.,v.3, São Paulo, 1949.

Religião Terêna. In: Schaden,E. (org.) Leitura de Etnografia Brasileira. São Paulo, Cia. Ed.Nacional,1976.p.268-276.

BARTH, F. 2000. O guru, o iniciador e outras variações antropológicas. Org. TomkeLaskeTradução de John Cunha Comerford. RJ: Contra Capa Livraria.

BELAUNDE, Luisa Elvira. 2006. "A força dos pensamentos, o fedor do sangue. Hematologia e gênero na Amazônia”. Revista de Antropologia, USP.

. 2015. “O estudo das sexualidades na etnologia.” In Cadernos de campo, São Paulo, n.24 p. 399-411. 2015

BUTLER, J. Problemas de gênero: feminismo e subversão da identidade. Rio de Janeiro: Civilização Brasileira, 2003.

CARNEIRO, A. 2015-a. “O sistema da mexida de cozinha”. In: Comerfor, Carneiro e Dainese. (orgs.). Giros etnográficos em Minas Gerais: conflito, casa, comida, prosa,festa, política e o diabo. Rio de Janeiro: 7Letras.

CARDOSO DE OLIVEIRA, R. 1976. Do índio ao bugre: o processo de assimilação dos Terena. $2^{\mathrm{a}}$ ed.revista. Rio de Janeiro, Livraria Francisco Alves.

. 1991. Introdução - Leitura de Rivers. In: CARDOSO DE OLIVEIRA, R. (Org.). Antropologia de Rivers. Tradução de Gilda Cardoso de Oliveira e Sonia Bloomfield Ramagem. Campinas, Editora Unicamp, p.7-48.

. 2000. O trabalho do antropólogo. $2^{\mathrm{a}}$ ed. São Paulo, UNESP. 


\section{Nanduty}

ISSN:2317-8590

Brasília, Editora UnB.

2002. Os diários e suas margens: viagem aos territórios Terêna e Tükúna.

CARVALHO, S. M. S. et al. 2001. Bibliografia crítica dos povos Aruák do Mato Grosso do Sul e do Grande Chaco. São Paulo, Terceira Margem.

CARVALHO,S.M.S. Chaco: encruzilhada de povos e 'melting por' cultural, suas relações com a Bacia do Paraná e o sul-mato-grossense. In: CUNHA, Manuela C. (Org). História dos índios no Brasil. São Paulo: Cia das Letras, FAPESP e S.M.C./SP, 1992, p. 457-474.

CAVALCANTE, T. L. V. 2011. "Etno-história e história indígena: questões sobre conceitos, métodos e relevância da pesquisa. ” História, São Paulo, 30 (1): 349-371.

CUNHA, M. C. da 2009. Cultura com aspas e outros ensaios. São Paulo: Cosac Naify.

DAINESE, G. e SERAGUZA, L. "Sobre gêneros, arte, sexualidade e a falibilidade destes e de outros conceitos” Revista Ñanduty, 2016.

DEBERT, G. G. 1983. Problemas relativos à utilização de histórias de vida e história oral. In: CARDOSO, Ruth (Org.). Aventura antropológica. Rio de Janeiro, Paz e Terra, p.141-156.

EREMITES DE OLIVEIRA, J. \& PEREIRA, L. M. 2007. "Duas no pé e uma na bunda": da participação terena na guerra entre o Paraguai e a Tríplice Aliança à luta pela ampliação de limites da Terra Indígena Buriti. História em Reflexão, Dourados, 1(2):1-20.

. 2012. Terra Indígena Buriti: perícia antropológica, arqueológica e histórica sobre uma terra terena na Serra de Maracaju, Mato Grosso do Sul. Dourados,Editora UFGD.

EVANS-PRITCHARD, E. E. Bruxaria, oráculos e magia entre os Azande; edição resumida e introdução, Eva Gillies; tradução Eduardo Viveiros de Castro.- Rio de Janeiro: Zahar, 2005.

FAVRET-SAADA, J. Ser afetado (tradução de Paula de Siqueira Lopes). Cadernos de Campo, n. 13, p. 155-161, 2005.

GEERTZ, C. A interpretação das Culturas. 1.ed. [Reimp.]. RJ LTC, 2013.

2005.

Obras e Vidas: o antropólogo como autor. 2 ed. Rio de Janeiro: Editora UFRJ,

GOLDMAN, M.; VIVEIROS DE CASTRO, E. Abaeté, rede de antropologia simétrica. Cadernos de Campo, n. 14/15, p. 177-190, 2006. (Entrevista concedida a Aristóteles Barcelos Neto, Danilo Ramos, Maíra Santi Bühler, Renato Sztutman, Stelio Marras e Valéria Macedo).

INGOLD, T. "Trazendo as coisas de volta à vida: Emaranhados criativos num mundo de materiais. Horizontes Antropológicos”, Porto Alegre, ano 18, n. 37, p. 25-44, jan./jun. 2012 


\section{Nanduty}

ISSN:2317-8590

LEVI-STRAUSS, C. O cru e o cozido: Mitológicas. São Paulo: Brasiliense, 1991.

As estruturas elementares do parentesco. Petrópolis: Ed. Vozes, 1982 [1969].

Tristes trópicos. São Paulo: Cia das Letras, $1^{\circ}$ reimpressão, 1998.

MALINOWSKI, B. 1984 [1922].Argonautas do Pacífico ocidental: um relato do empreendimento e da aventura dos nativos nos arquipélagos da Nova Guiné Melanésia. Tradução de A. P. Carr\& L. A. C.Mendonça. $3^{a}$ ed. São Paulo, Abril Cultural.

MAYBURY-LEWIS, D. O selvagem e o inocente. Tradução Mariza Corrêa. Editora UNICAMP, 1990.

MAUSS, M. Sociologia e antropologia, introdução por Claude Lévi-Strauss. Tradução: Paulo Neves. São Paulo: Cosac Naify, 2003.

OLIVEIRA L .C. Festa de Santos Reis: Patrimônio Imaterial de São Sebastião do ParaísoMinas Gerais. 2015. PUC-SP. Dissertação apresentada no Programa de Historia Social.

PANET, Rose-France. "I mã a kupên prâm!": prazer e sexualidade entre os Canela. São Luís, Maranhão, 2010. Tese (Doutorado) - Universidade Federal do Maranhão.

PACHECO DE OLIVEIRA, J. 1998. Uma etnologia dos "índios misturados"? Situação colonial, territorialização e fluxos culturais. Mana, São Paulo, 4(1):47-77.

Rio de Janeiro, Editora UFRJ.

1999. Ensaios em antropologia histórica. Prefácio de Roberto C. de Oliveira.

PEREIRA, L. M. 2008. Os Terena de Buriti: formas organizacionais, territorialização e representação da identidade étnica. Apresentação de Jorge Eremites de Oliveira. Dourados, Editora UFGD.

SALHINS, M. Ilhas de história. Rio de Janeiro: Jorge Zahar Ed., 1990.

, O "pessimismo sentimental" e a experiência etnográfica: por que a cultura não é um "objeto" em via de extinção (parte I e II). Mana Estudos de Antropologia Social - Revista do Programa de Pós Graduação em Antropologia Social do Museu Nacional da Universidade Federal do Rio de Janeiro. UFRJ,v.3, n.1 e2.1997.

SANTOS, M. R., PEDRO. J. M. E RIAL, C. "Novas práticas corporais no espaço doméstico: a domesticidade pop na revista Casa e Jardim durante os anos 1970" Copyright, 2012. By Revista Estudos feministas.

SCHNEIDER, D. M. Parentesco americano: uma exposição cultural; tradução de Fábio Ribeiro.- Petropólis, RJ. Vozes, 2016. - (coleção Antropologia). 


\section{Nanduty}

ISSN:2317-8590

STRATHERN, M. "Entre uma melanesianista e uma feminista". In: Cadernos Pagu (8/9) 1997:pp.7-49.

O Gênero da Dádiva. $1^{a}$ Ed., Apresentação de Adriana Piscitelli. Tradução de André Villa Lobos. Campinas/SP: Editora Unicamp, 2006.

SERAGUZA, L. 2016. Aty Guasu Kuña - sexualidade e relações de gênero entre os Kaiowa e Guarani. No prelo. 2016.

WOORTMANN, K. 1985. A comida, a família e a construção do gênero feminino. Série Antropologia, UnB, Brasília. 